\title{
The impact of COVID-19 on the spatial distribution of shooting violence in Buffalo, NY
}

\author{
Gregory Drake ${ }^{1}$ - Andrew P. Wheeler ${ }^{2}$ - Dae-Young Kim ${ }^{3}$ - Scott W. Phillips ${ }^{3}$. \\ Kathryn Mendolera ${ }^{4}$
}

Accepted: 23 November 2021

(c) The Author(s), under exclusive licence to Springer Nature B.V. 2021

\begin{abstract}
Objectives This paper examines the extent to which hotspots of shooting violence changed following the emergence of COVID-19.

Methods This analysis uses Andresen's Spatial Point Pattern test on 1500 by 1500 foot grid cells, correcting for multiple comparisons, on a 10-year sample of geocoded shooting data from Buffalo New York.

Results This work finds zero micro-grid cells are not statistically different from pre to post COVID stay at home orders and instead that the observed rise in shootings in the sample appears to be a consistent proportional increase across the city.

Conclusions These findings provide law enforcement with useful information about how to respond to the recent rise in shooting violence, but additional work is needed to better understand what, among a number of competing theories, is driving the increase.
\end{abstract}

Data and code used to replicate the analysis can be downloaded from https://www.dropbox.com/sh/ a4b8b2r88vg4i2i/AAAuU-c_RZpzHRuQ4knNir_5a?dl=0.

Gregory Drake

gdrake@sjfc.edu

Andrew P. Wheeler

apwheele@gmail.com

Dae-Young Kim

kimd@buffalostate.edu

Scott W. Phillips

phillisw@buffalostate.edu

Kathryn Mendolera

kmmendolera@bpdny.org

1 Saint John Fisher College, 3690 East Ave, Rochester, NY 14618, USA

2 HMS, 5615 High Point Dr \#100, Irving, TX 75038, USA

3 SUNY Buffalo State, 1300 Elmwood Ave, Buffalo, NY 14222, USA

4 Erie Crime Analysis Center, 68 Court St., Buffalo, NY 14202, USA 
Keywords COVID-19 $\cdot$ Spatial analysis $\cdot$ Hot spots $\cdot$ Gun violence $\cdot$ Shootings

\section{Introduction}

This paper examines the impact of the emergence of COVID-19 and subsequent stay at home order (SAHO) in Buffalo, a mid-sized urban center in upstate NY, on the spatial distribution of shootings. Specifically, with the understanding that shootings in Buffalo increased during the study period based on prior work (Kim and Phillips, 2021), this study is concerned with whether shooting locations remained stable but intensified in the volume of shooting violence, or if areas of shooting violence "shifted" in space following the emergence of COVID-19 and New York States SAHO. Understanding the spatial dynamics of these changes would be invaluable to police departments so that they can adjust police resources to better respond to an increased volume of shooting incidents.

Considering the national conversation about violent crime, particularly a rise in shooting violence in 2020 (Rosenfeld et al., 2021), it has become increasingly important to understand changes in violent crime beginning with the emergence of COVID-19 and the implementation of SAHO. In one of the few analyses of the impacts of COVID-19 and SAHO on shooting violence specifically, Kim and Phillips (2021) found a significant rise in shooting violence in Buffalo, New York, following the emergence of the pandemic and subsequent social distancing requirements.

The paper extends the prior work by examining whether spatial patterns of those shootings also changed. While there is a wealth of prior city-level analyses of changes in COVID crime patterns, few studies to date have examined spatial changes in addition to macro city-level changes. Given that one of the most popular interventions to reduce crime to date is hot spot policing (Braga et al., 2019), such a strategy is conditional on targeting small areas of higher prevalence of crime. Thus, this study contributes to the simple question of, in Buffalo, would a hot spot policing strategy targeting shootings need to update its targeted areas?

In short, the answer to this question is no. Using Andresen's Spatial Point Pattern Test (SPPT) at small grid cells over Buffalo, this study compares the relative distribution of shootings before versus after SAHO's were put in place in Buffalo (Andresen, 2016). Only slight variations are found in the density of shootings preto post-COVID, suggesting that despite the overall number of shootings clearly increasing in Buffalo, the spatial distribution of those shootings remained relatively constant.

\section{Literature review}

This literature review is organized around two topical areas. First, it reviews the contemporary literature on COVID and crime, particular the wealth of analyses that have been conducted at the city level and divergences across different crime types. This section also details the few tests of spatial divergences due to COVID across 
time. Second, it reviews historical analyses of the spatial distribution of shootings, in particular prior work that has examined historical volatility and spatial clustering of those shootings.

\section{Prior analyses of COVID and crime}

The emergence of COVID-19, and subsequent government mandated social distancing measures, changed life significantly in spring of 2020. These changes impacted social life in drastic ways, including significant reductions in employment, the closing of schools and afterschool programs, and even reductions in the use of public transit (Estevez-Soto, 2021; Scott \& Gross, 2021). Early research, often focusing on macro city level patterns, found mixed evidence that these disruptions resulted in changes in crime patterns. Often arguing from a routine activity theory perspective (Cohen \& Felson, 1979) that SAHO and other social distancing measures would reduce the intersection of offenders and victims, several studies found significant reduction in the crimes of residential burglary (Felson et al., 2020; Scott \& Gross, 2021), robbery (Balmori de la Miyar et al., 2020), and larceny (Estevez-Soto, 2021). Such declines, however, were not uniform. For example, in a study of 16 large American cities, Ashby (2020) found little evidence of obvious decreases nor increases due to short-term impacts of COVID SAHO's. Campedelli et al. (2020b), examining short-term changes in Chicago, reported little evidence of decreases or increased across a variety of crime types, but using the same methodology found some evidence for increases in instrumental crimes in Los Angeles (Campedelli et al., 2020a).

Despite the early possibility that the pandemic might reduce violent crime, with the likely exception of domestic violence (McLay, 2021), firearm violence has increased significantly in that time (Rosenfeld et al., 2021). Several studies have examined whether these increases can be attributed to gang violence (Balmori de la Miyar et al., 2020; Brantingham et al., 2021), under the presumption that gangs were unlikely to obey SAHO's. While Balmori de la Miyar et al. (2020) found evidence that specific gang crimes decreased in Mexico City while other crimes did not, Brantingham et al. (2021) showed no evidence of increased gang-related violence in Los Angeles. Kim and Phillips (2021), focused on shootings in Buffalo, New York, reported evidence that gang shootings increased, whereas non-gang related shootings did not.

So far, the studies described have for the most part focused on macro level city wide trends. The exception to this is Brantingham et al. (2021) who performed a superficial test showing that crime clustering did not change from pre- to postCOVID by examining the distribution of Moran's I for gang crimes. Two currently published studies have more explicitly examined spatial changes in crime due to COVID (Moise \& Piquero, 2021; Yang et al., 2021).

Moise \& Piquero (2021) examined the change in clustering of violent crime in the three months following the stay-at-home-order in Miami-Dade County. This work found an overall reduction in violent crime of $7 \%$ and, despite the presence of violent crime clusters (using a spatial scan clustering technique) in previous years, 
was unable to identify clusters during the study period. Given that this is only based on 3 months of follow-up data and that violent crime only changed by a small percent in Miami, it is possible that the scan technique lacked power to detect meaningful clusters in that time period.

Yang et al. (2021), using Andresen's SPPT (as is done in the current analyses of Buffalo data), found widespread changes in assaults, batteries, thefts, and criminal damage across census tracts in Chicago comparing crime before and after COVID. It should be noted that Yang et al. (2021) used a historical version of the SPPT that is known to result in a large number of false positives (Wheeler et al., 2018). This can be seen as they showed significant spatial changes in these crimes in time periods before COVID SAHO's in Chicago, which is contrary to nearly 100 years of spatial analysis of crime in Chicago showing long-term spatial consistency in crime patterns (Papachristos, 2013; Shaw \& McKay, 1969; Wheeler et al., 2021a).

While these studies have focused theoretically on COVID SAHO's, the timing of these orders is mostly confounded with the impact of social unrest following the death of George Floyd (Rosenfeld et al., 2021). Kim \& Phillips (2021) reported the increase more aligns with SAHO's than it does with Black Lives Matter protests in their study in Buffalo. Frustratingly, different popular criminological theories can be contorted to offer equivocal predictions under the current circumstances, especially given the confound with social unrest. For example, while SAHO's undoubtedly changed the routine activities of individuals, one could argue that motivated offenders are unlikely to obey government mandates and so can cause increases in certain crimes (Balmori de la Miyar et al., 2020). One can additionally point to potential de-policing in response to the pandemic as a possible mechanism by which crimes increase (Brantingham et al., 2021). While economic strain theories are often discussed as well (Rosenfeld et al., 2021), they too offer no obvious mechanism that would describe why some crimes decrease in some cities and not others. Given COVID is a pandemic, its effects are felt nearly everywhere across the world in a similar fashion. Similar arguments could be made for any spatial patterns of crimewithout explicit measures of offenders, victims, and guardians, any attribution of spatial crime changes post COVID due to routine activities (or other particular criminological theories) are quite tentative.

In short, while these prior studies are descriptive of crime changes around the time of SAHO's, they are not able to strongly attribute those changes to any specific causal impetus. This study has the same limitations, so while it can offer potential speculation as to why spatial patterns of crime may or may not change following SAHO's, it cannot definitively attribute those changes to any particular theory of crime.

\section{Spatial clustering of shootings}

The predominate theme in the spatial analysis of crime is that most crime clusters into a smaller number of places, regarded as Weisburd's Law of Crime Concentration (Weisburd, 2015). This clustering is also true of shootings (Braga et al., 2010) but shows extreme volatility. Even though in the long run certain places have 
long-term, historically higher densities of shootings, given the rarity of shootings they tend to come in bursts, showing significant spatial and temporal clusters.

For example, analysis showing such spatial and temporal clusters, Larsen et al. (2017) used a spatial scan statistic to identify clustering of shootings incidents in several places of Syracuse, New York, over a seven-year period. These clusters appeared to not be ephemeral though-one of the clusters would be considered quite a large area, encompassing several high crime neighborhoods in western Syracuse. All the identified temporal clusters spanned multiple years over the study period, also suggesting historical persistence in shootings (at least over the study period).

Other criminologists examined the near repeat patterns of shootings (Ratcliffe \& Rengert, 2008; Wheeler et al., 2021a; Wheeler et al., 2021b; Wyant et al., 2012). This research forms a statistical test to identify how frequently different pairs of shootings occur nearby in time and space. The logic behind such clustering is retaliatory violence. These tests often reported that shootings significantly cluster within a few weeks and a few thousand feet of each other.

Despite these studies though, it appears shootings, like other crimes (Andresen et al., 2017), show historical consistency when modelling the underlying intensity over time. For example, Loeffler \& Flaxman (2018), examining shootings recorded via acoustic sensors in Washington, D.C., showed that the major temporal trends in shootings cannot be attributed to near-repeat patterns but are more likely explained by a smoothly varying temporal trend, along with an independent historical estimate of the shooting density over time. In total, although short, temporal bursts where shootings increase appear to be not uncommon, historically they do not appear to substantively shift the spatial locations of where those shootings occur.

None of the cited studies have strong empirical arguments for why such spatial consistency should be the norm and when it might change. It may be that the built environment significantly shapes where crimes can occur, causing crime and place to be sticky (Weisburd, 2015), since the built environment (e.g., residential apartments, commercial zoning) is quite consistent over time. It may also be the case that particular human influences, such as the border of gang territories (Papachristos et al., 2013), influence where shootings take place. While this may suggest spatial patterns would change when gangs and their territories churn over time, it is known that this is not the case with general crime patterns based on historical work in social disorganization theory (Shaw \& McKay, 1969). It may be for the same reasons due to the built environment that particular locations generate more violent conflict, and so even if the immediate causal antecedent for a shooting is attributable to gang violence, the spatial distribution may still be heavily influenced by the unchanging built environment.

Similar to the prior section on the limited ability of this study to uncover causal reasons for overall crime increases, this study cannot say much about potential reasons for why crime may be spatially consistent or may move. That being said, even without being able to make strong causal statements, it is still relatively useful from a policy perspective-specifically when considering a hot spot policing strategywhether those hot spots of shootings have shifted during the recent increase. If they have, it would behoove a police department to more regularly monitor spatial patterns and adjust their targeted areas accordingly. It may be the case that prior studies 
showing long-term consistency in crime and place are not as relevant for short-term dramatic increases. This analysis is intended to determine whether such spatial shifts in shooting hot spots happened in Buffalo after the COVID SAHOs. Specifically, we hypothesize that despite the disruptions to social life brought by COVID-19 and subsequent SAHOs, shooting violence will remain largely stable during the study period, consistent with Weisburd's (2015) description of the "stickiness" of crime in space. And we subsequently conduct statistical analysis to determine if we can reject that null hypothesis that the spatial distribution of crime is relatively consistent over time.

\section{Methodology}

\section{Data}

The data we use for the analyses are address geocoded shooting locations with a victim (which includes subsequent homicides), provided by the Buffalo Police Department (BPD) from 2010 through June 17, 2021. This includes a total of 2481 shootings over the 4155 days, so approximately on average one shooting every other day. Geocoding hit rates over the time period are extremely high, greater than $99 \%$, with only a few incidents without a usable address.

Table 1 provides summary statistics for the citywide trends in shootings. Prior analysis in Buffalo has shown an increase in shootings post-COVID stay at home orders in Buffalo (Kim \& Phillips, 2021), which occurred on March 23, 2020. This simple table shows a similar story for all shootings, with an average varying from 13 to 18 shootings per 30 days citywide in the time period of 2010-2019. The year

Table 1 Total shootings per year and during pre-/post-COVID period (post-COVID are dates starting March 23, 2020, and sample collection ends June 17, 2021)

\begin{tabular}{llll}
\hline Year & Shootings & Days in sample & $\begin{array}{l}\text { Shoot- } \\
\text { ings per } \\
30 \text { days }\end{array}$ \\
\hline 2010 & 218 & 365 & 18 \\
2011 & 223 & 365 & 18 \\
2012 & 213 & 366 & 17 \\
2013 & 171 & 365 & 14 \\
2014 & 200 & 365 & 16 \\
2015 & 205 & 365 & 17 \\
2016 & 258 & 366 & 21 \\
2017 & 202 & 365 & 17 \\
2018 & 206 & 365 & 17 \\
2019 & 159 & 365 & 13 \\
2020 & 293 & 366 & 24 \\
2021 & 133 & 137 & 29 \\
Pre-COVID & 2081 & 3734 & 17 \\
Post-COVID & 400 & 421 & 29 \\
\hline
\end{tabular}


2020 and 2021 saw clear increases in the total number of shootings, with an increase to 28 shootings per 30 days vs an average of 17 shootings per 30 days in the prior 10 years.

\section{Analysis plan}

This analysis focuses on two particular estimates for the analysis. First, it estimates the relative distribution of shootings using Andresen's Spatial Point Pattern Test (SPPT) (Andresen, 2016). This test examines the proportion of crimes falling in a particular spatial unit in two samples. For a hypothetical example, suppose the historical sample area A has approximately $4 \%$ of the total shootings, and in the contemporary sample area A has $8 \%$ of the total shootings. One then forms a statistical test to compare the $4 \%$ to the $8 \%$. One then does this same statistical test for each of the areas in the study region. Based on the statistical test (here a Chi-Square test), one can subsequently formulate an overall index of similarity between the two patterns when one fails to reject the null hypothesis that the two proportions are equal. The proportion of areas that are considered equal is the $S$ index (Andresen, 2016). One can additionally map out the spatial patterns of the overall difference between the two samples, to identify particular spatial patterns, such as shifts or clusters of differences.

This test is particularly useful for police agencies, as it can be employed to identify changes in the rank ordering of the highest crime places, which is often used to prioritize hot spots of crime. For example, if in the pre-time period the area with the most crime had $2 \%$ of the total incidents, and in the post time period had only $1 \%$ of the total incidents, it can be assumed that it likely resulted in decreasing in relative importance in terms of prioritizing that area as a hot spot. It may be crime spread out more evenly overall, or other areas eclipsed that hot spot in the relative ranking. But the test is not limited to only examining hot spots, which are ultimately arbitrary designations (Taylor, 2015). That is, one could identify changes in an area that is higher crime, but not originally considered a hot spot, in either direction (decreasing overall proportions or increasing overall proportions). It is for this reason that the SPPT test is preferred over creating hot spot clusters in pre- and post-COVID time periods, as was done by Moise and Piquero (2021). The SPPT has been used in numerous prior publications to identify relative spatial changes over time (e.g., Andresen \& Malleson, 2014; Hodgkinson et al., 2016; Linning, 2015; Vandeviver \& Steenbeek, 2019).

SPPT analysis requires choosing a spatial unit of analysis to compare proportions. There is ultimately a trade off in determining the area (Ramos et al., 2021). Too large and one is arguably not examining hot spots, but more general neighborhood spatial patterns. Too small, and one lacks the power to detect any meaningful changes. This study created a set of regular grids over the study area of 1500 by 1500 feet (using the New York State plane west projection).

The reason for these sized areas follows the power analysis logic first described in Wheeler (2021). In short, this is the sized area that gives a power of over 0.7 to detect a change in the relative distribution from a location at the 80th percentile 
to the 20th percentile, assuming the spatial patterns follow a slightly overdispersed negative binomial distribution. While these are generally larger areas than Buffalo Police considers hot spots for some interventions (Wheeler \& Phillips, 2018), in conferring with the Buffalo crime analysts, the department does not have a fixed, regular, designation that they consider to be a hot spot. And in sharing internal maps the analysis unit disseminates, 1500 by 1500 foot areas in general aligned with the areas they currently identify as hot spots of shooting crimes. This analysis only examines grid cells in Buffalo that had at least one shooting over the entire study period, which resulted in a total of 298 grid cells under examination. Figure 1 displays these grid cells, along with a background map of Buffalo.

To examine the differences, this study uses the procedure outlined in Wheeler et al. (2018) to test the differences in proportions, using the Chi-square test with Yates continuity correction. Unlike the original SPPT test, this does not require one set a base and a test dataset, the analysis is invariant to that decision. Additionally, this analysis adjusted the p-values for multiple comparisons using the procedure discussed in Benjamini \& Yekutieli (2001) to control the overall false discovery rate, as this adjustment allows for the tests to be correlated. This adjustment is important, because when making many individual hypothesis tests (here 298), one would expect some of them to reject the null hypothesis simply by chance. The methods for the analysis are implemented in the R package sppt (Steenbeek et al., 2020).

For the second analysis, this study focuses on examining the absolute increase in the shooting intensity in those same grid cells, comparing the overall numbers of shootings per unit time before and after COVID SAHO. Even if the relative spatial patterns do not move, given how shootings increased overall in Buffalo (Kim \& Phillips, 2021), it may be the case that the overall increase in intensity would suggest hot spot areas should be expanded to include new areas. Ultimately BPD needs to decide on whether the intensity of crime at a particular area justifies the investment of allocating additional policing resources (Wheeler \& Reuter, 2021).

This study examines the changes in the shooting counts using normal-based approximations to the Poisson distribution (Wheeler \& Ratcliffe, 2018). Although shootings are generally overdispersed compared to the Poisson distribution, this overdispersion tends to not greatly impact overall coverage of confidence intervals in actual shooting data with simple adjustments (Wheeler, 2016). Here the analysis uses a suggestion by Wheeler (2016) and applies confidence intervals at Z-scores, instead of the typical Z-scores, to examine relative changes in the shooting counts between two distributions in the same 298 grid cells. Data and code used to replicate the analysis can be downloaded from https://www.dropbox.com/sh/a4b8b2r88v g4i2i/AAAuU-c_RZpzHRuQ4knNir_5a?dl=0.

\section{Results}

\section{SPPT analysis}

In first presenting the SPPT results, with the unadjusted $p$ values, this analysis identifies a total of 35 areas that had a $p$ value under 0.05 . Figure 2 displays a histogram 


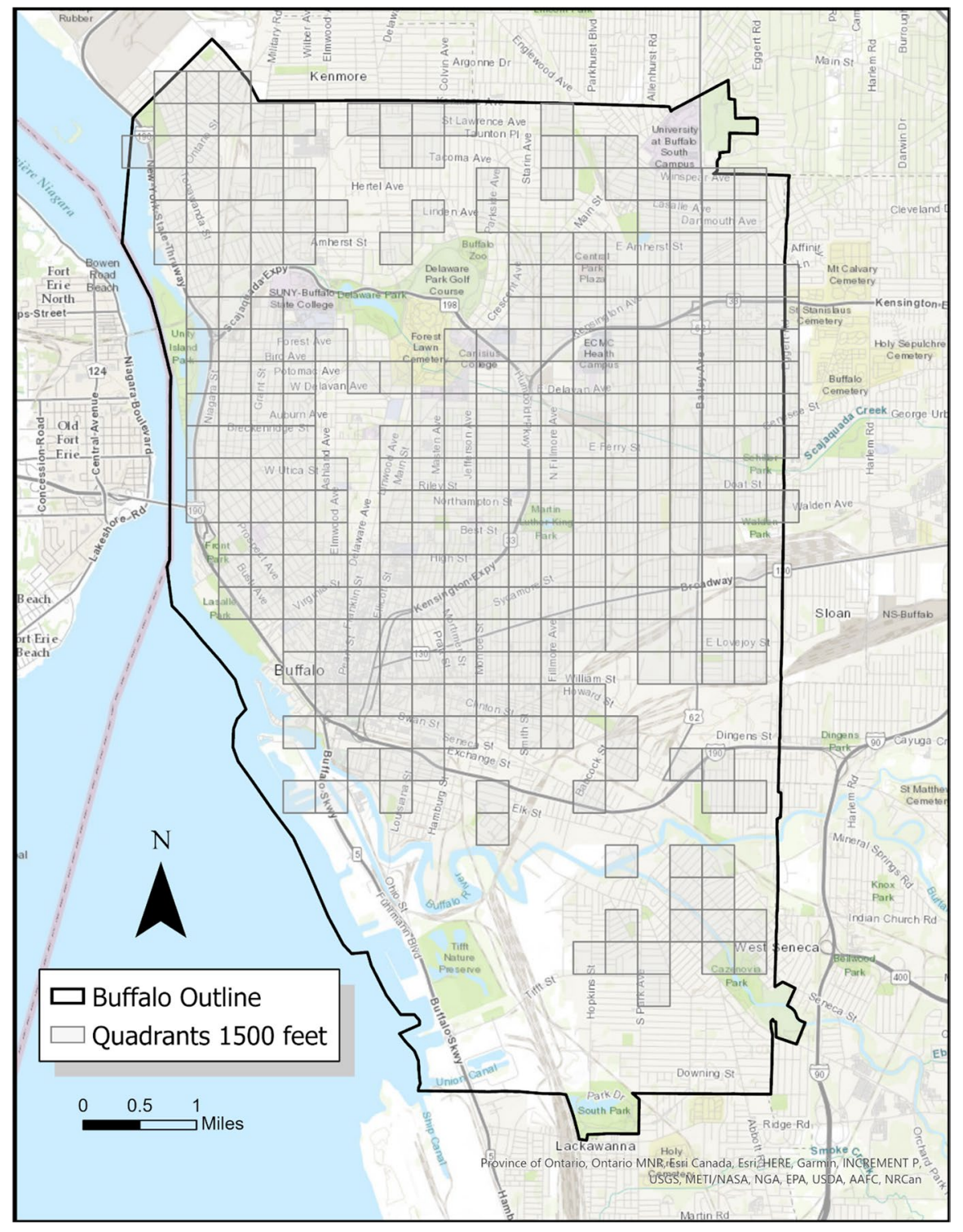

Fig. 1 Buffalo study area, with 298 grid 1500 by 1500 foot grid cells that had at least 1 shooting over the 11-year period

of those $p$ values, showing that while there is a slight spike at the 0.05 level; overall the results are quite uniform, with the exception of several spikes, which occur because of the discrete nature of the outcome (e.g., multiple grid cells changing from 0 to 1 or 1 to 0 shootings in the pre-post periods). $p$ values under the null of no changes would also be expected to have a uniform distribution. Based on the unadjusted $p$ values and using an alpha level of 0.05 , one would then have a similarity 
Fig. 2 Histogram of 298 unadjusted p-values from SPPT analysis. Test examines difference in proportions for the two point patterns in 2981500 by 1500 foot quadrants over Buffalo. The test used is the Chi-Square with Yates continuity correction

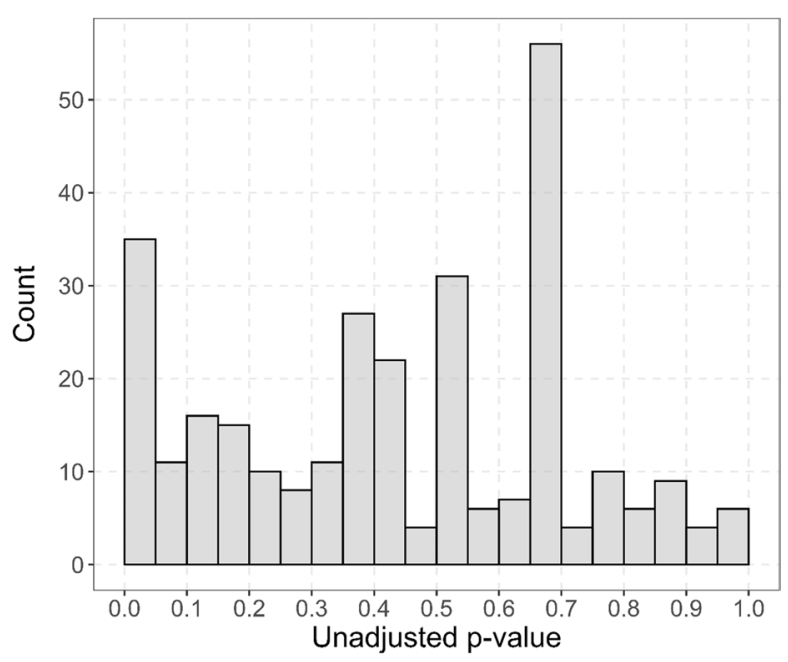

S-index of 0.88 , considered typically to be quite similar between two-point patterns (Andresen, 2016). For example, of the 35 areas that were flagged as different, one area had 32 shootings in the pre-period, a total of $1.5 \%$ of all shootings, and 0 shootings in the post-COVID period, so a difference of $1.5 \%$ and a subsequent continuity corrected Chi-square $p$ value of 0.012 (given the overall sample sizes). For a change in the opposite direction, one area had 13 shootings in the pre-period $(0.6 \%)$ and 10 shootings in the post period (2.5\%), for a $p$ value of less than 0.001 .

But this does not take into account multiple comparisons. With 298 tests, one would expect simply by chance approximately 15 areas to be under the typical 0.05 alpha level without adjustment. Using a false discovery rate correction that considers how tests may be correlated resulted in zero adjusted $p$ values below the 0.05 threshold. After adjusting the $p$ values, the smallest adjusted $p$ value for the SPPT comparisons is over 0.3 .

While two of the examples stated appear on their face to potentially be substantively different proportions, the majority of the differences are only a few shootings (e.g., 0 in pre and 1 in post in this framework is a statistically significant difference). Although on its face the SPPT test has some power to detect differences, when correcting for multiple comparisons in this sample there is no substantive evidence that the relative distribution of shootings changed.

\section{Differences in crime counts}

Figure 3 displays the total counts of shootings in the pre-COVID period and the post-COVID period in a scatterplot for the 298 areas. Points are slightly jittered in each dimension in a random fashion (so can be shifted -0.3 to +0.3 on both the $X$ or $\mathrm{Y}$ axis) to prevent overlapping points, especially at lower overall crime counts. One can see that the two patterns have a fairly strong correlation (a Pearson correlation coefficient of 0.6), although a few areas are outside of the predicted areas according to the Poisson distribution. The contour lines display the ratio of 0.19 , 


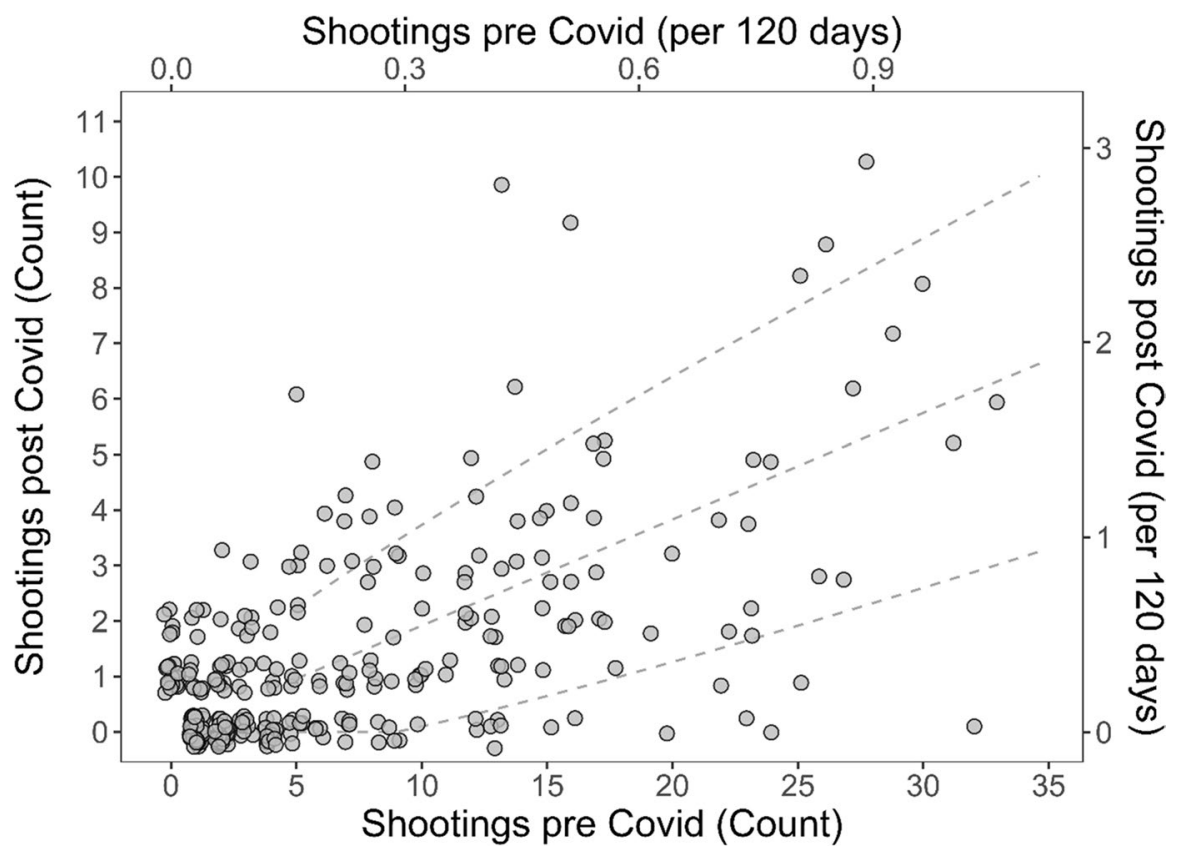

Fig. 3 Total number of shootings in pre Covid time period per quadrant vs post-COVID time period. Points are slightly jittered in each dimension to prevent overlapping. Contour lines represent a change of 0.19 from pre to post, and are the normal based approximations to the Poisson distribution at Z-scores of $-3,0$, and 3.The Pearson correlation between the two patterns is 0.6

which is based on the overall citywide changes in the total number of shootings (i.e. 400/2081). If the increases were equally spread out in terms of ratios for the original baseline counts, the post-COVID counts would approximately follow the centerline. The outside contour lines are based on the normal approximation to the Poisson differences (Wheeler, 2016; Wheeler \& Ratcliffe, 2018) for Poisson Z-values of -3 to 3.

While some locations are outside of the bands, many are barely outside, suggesting a swing of only one or two shootings outside of normal. Since this is spread out over a year of post-COVID time period, this again does not seem to be a substantively different pattern to suggest dramatically shifting shooting hot spot patterns based on this analysis. It is more likely the Poisson distribution assumption is not reasonable, and so the extra variance (likely from shootings being overdispersed, Berk \& MacDonald, 2008) is what accounts for different in the overall rates over time.

Figure 4 displays a map of the shooting incidents per 120 days for the pre- and post-COVID time periods, as well as a difference in the overall intensity. One can see the area with the most shootings in the post-COVID time period, the centraleast portion of Buffalo in the center map was a high shooting area (although not the highest), in the pre-COVID time period. The difference map on the right-hand side displays these areas of increased shooting intensity as purple grid cells, whereas 


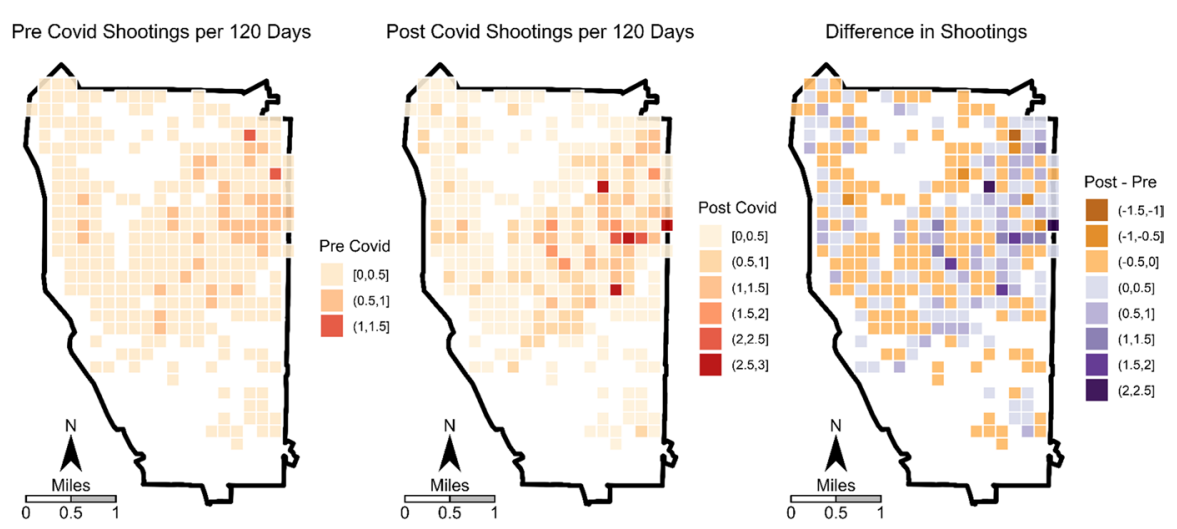

Fig. 4 Shooting intensity standardized per 120 days for each grid cell in pre and post-COVID time periods, and comparison of the difference

the orange scale cells indicate overall decreases in the intensity of shootings. While these are suggestive of some areas of increased intensity, these still appear to largely mimic the historical areas of high gun crimes. As such, these results do not provide strong evidence suggesting that hot spots have significantly shifted in space, only intensified, during the post-COVID time period.

\section{Conclusion}

While a large number of studies have examined temporal changes in crime postCOVID stay at home orders (Andresen \& Hodgkinson, 2020; Ashby, 2020; Balmori de la Miyar et al., 2020; Campedelli et al., 2020a; Campedelli et al., 2020b; Kim \& Phillips, 2021), changes in geographic patterns have been less studied (Moise \& Piquero, 2021). Consistent with our hypothesis and Weisburd's description of the temporospatial patterns of crime as sticky, this study finds little evidence to suggest substantive shifts in the relative spatial distribution of shootings in Buffalo; areas that were already hot spots of crime increased in intensity.

Subsequently in terms of practical policy consideration, while Buffalo PD is more justified in a hot spots strategy now than it was prior to the shooting increases, as the hot spots contain more shootings now than before, it is unclear if the overall shooting intensity justifies a hot spot strategy at all (Wheeler \& Reuter, 2021). Even the areas of most intensity in the maps show an average of fewer than 3 shootings per 120 days. Given that a high-end estimate of the average effectiveness of hot spots policing is around 20\% (Braga \& Weisburd, 2020), this would suggest where Buffalo PD to undertake a hot spots strategy in a single grid cell, it would perhaps only reduce one or two shootings in that grid cell per year. While not trivial, it would also require expanding a hot spots intervention to many areas to generate a significant overall reduction in shootings in Buffalo.

As such, it is doubtful that the intensity of shootings in many locations provides a large enough baseline to justify a proactive police response in the form of a hots 
spot strategy. The simple application of additional police resources may not generate a noticeable reduction in area shootings. This analysis does not suggest that other potential interventions, potentially other people based strategies, such as focusing on chronic gun offenders, group based interventions, or violence interrupters cannot be more effective strategies than place based hot spots strategies to combat the recent increases in shootings (Braga et al., 2018; Butts et al., 2015; Wheeler et al., 2019). Such interventions are not per se geographically constrained and so can potentially reduce shootings citywide, as opposed to be limited to specific geographic areas.

It may also be the case that focusing on detective resources to clear shootings may be more fruitful as well (Cook et al., 2019). While much more tentative than research at hot spots, there is some evidence that increasing clearances of shootings can result in subsequently reduced near repeat shooting events (Wheeler et al., 2021b; Wyant et al., 2012). It does appear that Buffalo overall has a low clearance rate for shootings, and that it has gone down slightly in the post SAHO period (Phillips et al., in press).

In terms of theory, unfortunately the research design allows limited comment. Popular spatial theories of criminology, such as routine activities theory (RAT), social disorganization, or economic strain, offer equivocal predictions. For RAT, one could say SAHOs decrease the potential interactions between offenders and victims. It could also be argued that SAHOs decrease the number of potential guardians on the street (Hipp, 2016). One could attribute increased intensity of shootings in prior high crime areas due to economic strain, but in terms of geographic patterns, those same strains were placed on everyone and everywhere, not just those in previously socially disorganized neighborhoods.

Several implications should be discussed for future research. This study used aggregate data, which do not distinguish the motivations behind gun violence, and where it occurred. Thus, future research should develop more specific research questions and hypotheses designed to explain how the pandemic has differently influenced gun violence across various crime motivations and locations. Routine activity theory suggests that there is an increase in crime if motivated offenders, suitable targets, and a lack of guardianship converge in time and place. Due to the pandemic and SAHOs and corresponding changes in daily routines, the relative spatial patterns in gun violence would move from residential to non-residential places, or vice versa, depending on crime motivations and locations.

For example, gun violence might disproportionately increase in domestic settings, as opposed to public spaces. This is because the pandemic and resulting SAHOs forced both offenders and victims to spend more time together in their homes. It is more difficult for victims to report such episodes and to seek help from the police and other resources. In addition, gun violence associated with burglary and robbery in non-residential spaces might disproportionately increase on the streets during the pandemic in the absence of capable guardianship, especially due to depolicing, while it might decrease in residential areas more people spend more time in their homes and guard their property from offenders.

If the long-term disaggregated data of gang- versus nongang-related shootings are available, future research can examine what effect the pandemic had on the spatial patterns of gang violence, as opposed to nongang violence. Given that 
most gang-related shootings took place in public spaces (Brantingham et al., 2021), it would be beneficial to test whether the SAHOs changed where gangs engage in shootings from public to residential spaces, or if they still do the same at the same places despite the enforcement of the SAHOs. It should be noted that there are potential errors in defining and measuring what constitutes gang violence, and there are wide variations across jurisdictions. Great caution is warranted for cross-sectional studies that compare gun violence across jurisdictions.

Given that the goal of the current study is to explore spatial changes in gun violence, it does not suggest why gun violence significantly increased during the pandemic. According to strain theory, crime tends to increase in society when and where individuals are deprived of legitimate opportunities for monetary success (Merton, 1938; Messner \& Rosenfeld, 2006) or experience other types of stress and strain, such as failing to achieve valued goals, withdrawal of positively valued stimuli, and confrontation with unwanted stimuli (Agnew, 2006). Future research is needed to investigate how much of the increase in gun violence resulted from increased unemployment, poverty, economic inequality, weakened non-economic social institutions (education, religion, and the family), and so on. However, the unavailability of weekly or monthly information on potential variables often precludes such research endeavors.

It is also important to acknowledge study limitations when interpreting the results. First, while attempting to control the grid size for analysis to generate a reasonable amount of power to detect spatial differences, it may be the case that overall the analysis still lacks power to detect what are meaningful changes in hot spots of shooting violence. While several areas of large increases or decreases are identified, and those are leads which Buffalo crime analysts might investigate further, it may be the results presented here are ultimately still quite conservative. This is especially the case when considering the analysis after adjusting for multiple comparison corrections, which corrects for overall Type I errors (rejecting the null when one should not have) but comes at the expense of potentially making more Type II errors (failing to reject the null when one should have). Even if one prefers the analysis with the unadjusted $p$ values, the results indicated overall quite a large number of grid cells, nearly $90 \%$, that do not significantly change in their overall proportion of shootings from pre to post SAHO in Buffalo.

A second limitation of the study is that all shooting incidents are pooled together, and do not distinguish between different motives for the shootings. These data do not have historical measures of gang related shootings, they are only available for the most recent few years from Buffalo PD (Kim and Phillips, 2021). As such it is possible that the results of no relative changes in the shooting distribution over time are masked by differential spatial changes in gang vs non-gang shootings. While this potential scenario with the pooled shooting data cannot be ruled out, it is unlikely and convoluted (one would need offsetting increases/decreases in the two types of shootings to result in estimates that show no spatial change).

A final limitation explicitly noted is that this analysis is based on shootings in one city. It is unclear to the extent that the results will be applicable to either other cities that have experienced increased shootings post pandemic, or to other crimes even within Buffalo. Given the extreme amount of heterogeneity in COVID and 
crime changes in macro-level research, it seems likely that such variance would also extend to spatial analyses as well.

The fact that this study did not find substantive evidence for significant spatial crime changes, it does suggest the stickiness of crime and place (Weisburd, 2015). Even in a time of great crime trend changes, it suggests the spatial distribution of high crime places is relatively static. Thus, while temporal crime patterns may substantively change over time, like prior work this study finds that spatial patterns are relatively consistent over time, even in the face of the large social upheaval that came with the emergence of COVID-19 (Loeffler \& Flaxman, 2018, Weisburd et al., 2004; Wheeler et al., 2016).

Supplementary Information The online version contains supplementary material available at https://doi. org/10.1007/s11292-021-09497-4.

\section{References}

Agnew, R. (2006). Pressured into crime: An overview of general strain theory. Roxbury Publishing.

Andresen, M. A. (2016). An area-based nonparametric spatial point pattern test: The test, its applications, and the future. Methodological Innovations, 9, 2059799116630659.

Andresen, M. A., Curman, A. S., \& Linning, S. J. (2017). The trajectories of crime at places: Understanding the patterns of disaggregated crime types. Journal of Quantitative Criminology, 33(3), 427-449.

Andresen, M. A., \& Hodgkinson, T. (2020). Somehow I always end up alone: COVID-19, social isolation and crime in Queensland, Australia. Crime Science, 9(1), 1-20. https://doi.org/10.1186/ s40163-020-00135-4

Andresen, M. A., \& Malleson, N. (2014). Police foot patrol and crime displacement: A local analysis. Journal of Contemporary Criminal Justice, 30(2), 186-199.

Ashby, M. (2020). Initial evidence on the relationship between the coronavirus pandemic and crime in the United States. Crime Science, 9(6), 1-16. https://doi.org/10.1186/s40163-020-00117-6.pdf

Balmori de la Miyar, J. R., Hoehn-Velasco, L., \& Silverio-Murillo, A. (2020). Druglords don't stay at home: COVID-19 pandemic and crime patterns in Mexico City. Journal of Criminal Justice. https:// doi.org/10.1016/j.jcrimjus.2020.101745

Berk, R., \& MacDonald, J. M. (2008). Overdispersion and Poisson regression. Journal of Quantitative Criminology, 24(3), 269-284.

Benjamini, Y., \& Yekutieli, D. (2001). Control of the false discovery rate in multiple testing under dependency. The Annals of Statistics, 29(4), 1165-1188.

Braga, A. A., Papachristos, A. V., \& Hureau, D. M. (2010). The concentration and stability of gun violence at micro places in Boston, 1980-2008. Journal of Quantitative Criminology, 26, 33-53.

Braga, A. A., Turchan, B. S., Papachristos, A. V., \& Hureau, D. M. (2019). Hot spots policing and crime reduction: An update of an ongoing systematic review and meta-analysis. Journal of Experimental CriminOlogy, 15(3), 289-311.

Braga, A. A., \& Weisburd, D. L. (2020). Does Hot Spots Policing Have Meaningful Impacts on Crime? Findings from An Alternative Approach to Estimating Effect Sizes from Place-Based Program Evaluations. Journal of Quantitative Criminology, Online First

Braga, A. A., Weisburd, D., \& Turchan, B. (2018). Focused deterrence strategies and crime control: An updated systematic review and meta-analysis of the empirical evidence. Criminology \& Public Policy, 17(1), 205-250.

Brantingham, J. P., Tita, G. E., \& Mohler, G. (2021). Gang-related crime in Los Angeles remained stable following COVID-19 social distancing orders. Criminology \& Public Policy.

Butts, J. A., Roman, C. G., Bostwick, L., \& Porter, J. R. (2015). Cure violence: A public health model to reduce gun violence. Annual Review of Public Health, 36, 39-53. 
Campedelli, G. M., Aziani, A., \& Favarin, S. (2020a). Exploring the immediate effects of COVID-19 containment policies on crime: An empirical analysis of the short-term aftermath in Los Angeles. American Journal of Criminal Justice. https://doi.org/10.1007/s12103-020-09578-6

Campedelli, G. M., Favarin, S., Aziani, A., \& Piquero, A. R. (2020b). Disentangling community-level changes in crime trends during the COVID-19 pandemic in Chicago. Crime Science, 9(1), 1-18.

Cohen, L. E., \& Felson, M. (1979). Social change and crime rate trends: A routine activities approach. American Sociological Review, 44(4), 588-608.

Cook, P. J., Braga, A. A., Turchan, B. S., \& Barao, L. M. (2019). Why do gun murders have a higher clearance rate than gunshot assaults? Criminology \& Public Policy, 18(3), 525-551.

Estevez-Soto, P. (2021). Crime and COVID-19: Effect of changes in routine activity in Mexico City. Crime Science, 10(15), 1-17.

Felson, M., Jiang, S., \& Xu, Y. (2020). Routine activity effects of the Covid-19 pandemic on burglary in Detroit, March 2020. Crime Science, 9(10), 1-7.

Hipp, J. R. (2016). General theory of spatial crime patterns. Criminology, 54(4), 653-679.

Hodgkinson, T., Andresen, M. A., \& Farrell, G. (2016). The decline and locational shift of automotive theft: A local level analysis. Journal of Criminal Justice, 44(1), 49-57.

Kim, D. Y., \& Phillips, S. W. (2021). When COVID-19 and guns meet: A rise in shootings. Journal of Criminal Justice, 73, 101783.

Larsen, D. A., Lane, S., Jennings-Bey, T., Haygood-El, A., Brundage, K., \& Rubinstein, R. A. (2017). Spatio-temporal patterns of gun violence in Syracuse, New York 2009-2015. PLoS One, 12(3), e0173001.

Linning, S. J. (2015). Crime seasonality and the micro-spatial patterns of property crime in Vancouver, BC and Ottawa On. Journal of Criminal Justice, 43(6), 544-555.

Loeffler, C., \& Flaxman, S. (2018). Is gun violence contagious? A spatiotemporal test. Journal of Quantitative Criminology, 34(4), 999-1017.

McLay, M. (2021). When "Shelter-in-Place" isn't shelter that's safe: A rapid analysis of domestic violence case differences during the COVID-19 pandemic and Stay-at-Home orders. Journal of Family Violence. https://doi.org/10.1007/s10896-020-00225-6

Merton, R. (1938). Social structure and anomie. American Sociological Review, 3, 672-682.

Messner, S. F., \& Rosenfeld, R. (2006). Crime and the American dream. Belmont, CA: Wadsworth

Moise, I. K., \& Piquero, A. R. (2021). Geographic disparities in violent crime during the COVID-19 lockdown in Miami-Dade County, Florida, 2018-2020. Journal of Experimental Criminology, 1-10. https://doi.org/10.1007/s11292-021-09474-x. Online ahead of print.

Papachristos, A.V. (2013). 48 years of crime in Chicago: A descriptive analysis of serious crime trends from 1965 to 2013. Yale, Institution for Social and Policy Studies working paper. Obtained from http://images.politico.com/global/2013/12/15/48yearsofcrime_final_ispsworkingpaper023.pdf on $5 / 21 / 2017$

Papachristos, A. V., Hureau, D. M., \& Braga, A. A. (2013). The corner and the crew: The influence of geography and social networks on gang violence. American Sociological Review, 78(3), 417-447.

Phillips, S.W., Drake, G.M., \& Althiemer, I. (in press). A stand-alone investigative unit to solve non-fatal shooting cases. International Journal of Police Science and Management.

Ramos, R. G., Silva, B. F., Clarke, K. C., \& Prates, M. (2021). Too fine to be good? Issues of granularity, uniformity and error in spatial crime analysis. Journal of Quantitative Criminology, 37(2), 419-443.

Ratcliffe, J. H., \& Rengert, G. F. (2008). Near repeat Patterns in Philadelphia Shootings. Security Journal, 21(1-2), 58-76.

Rosenfeld, R., Abt, T. \& Lopez, E. (2021). Pandemic, Social Unrest and Crime in U.S. Cities: 2020 YearEnd Update. Washington, D.C.: Council on Criminal Justice

Scott, S. \& Gross, L. (2021). COVID-19 and crime: Analysis of crime dynamics amidst social distancing protocols. PLOS ONE 16(4), 1-14. https://doi.org/10.1371/journal.pone.0249414

Shaw, C. R., \& McKay, H. D. (1969). Juvenile delinquency and urban areas: A study of rates of delinquency in relation to differential characteristics of local communities in American cities (2nd ed.). University of Chicago Press.

Steenbeek, W., Vandeviver, C. Andresen, M.A., Malleson, N., \& Wheeler, A. (2020) sppt: Spatial Point Pattern Test. R package version 0.2.3. https://github.com/wsteenbeek/sppt. Accessed 8/01/2021.

Taylor, R. (2015). Community Criminology. New York University Press.

Vandeviver, C., \& Steenbeek, W. (2019). The (in)stability of residential burglary patterns on street segments: The case of Antwerp, Belgium 2005-2016. Journal of Quantitative Criminology, 35(1), 111-133. 
Weisburd, D. (2015). The law of crime concentration and the criminology of place. Criminology, 53(2), 133-157.

Weisburd, D., Bushway, S., Lum, C., \& Yang, S. M. (2004). Trajectories of crime at places: A longitudinal study of street segments in the city of Seattle. Criminology, 42(2), 283-322.

Wheeler, A. P. (2016). Tables and graphs for monitoring temporal crime trends: Translating theory into practical crime analysis advice. International Journal of Police Science \& Management, 18(3), $159-172$.

Wheeler, A.P. (2021). Spatial sample size suggestions for SPPT analysis. https://andrewpwheeler.com/ 2021/07/03/spatial-sample-size-suggestions-for-sppt-analysis/. Accessed 8/01/2021.

Wheeler, A. P., Herrmann, C. R., \& Block, R. (2021a). Micro-place Homicide Patterns in Chicago: 1965-2017. Springer.

Wheeler, A. P., \& Phillips, S. W. (2018). A quasi-experimental evaluation using roadblocks and automatic license plate readers to reduce crime in Buffalo NY. Security Journal, 31(1), 190-207.

Wheeler, A. P., \& Ratcliffe, J. H. (2018). A simple weighted displacement difference test to evaluate place based crime interventions. Crime Science, 7(1), 1-9.

Wheeler, A. P., \& Reuter, S. (2021). Redrawing hot spots of crime in Dallas Texas. Police Quarterly, 24(2), 159-184.

Wheeler, A. P., Riddell, J. R., \& Haberman, C. P. (2021b). Breaking the chain: How arrests reduce the probability of near repeat crimes. Criminal Justice Review, 46(2), 236-258.

Wheeler, A. P., Steenbeek, W., \& Andresen, M. A. (2018). Testing for similarity in area-based spatial patterns: Alternative methods to Andresen's spatial point pattern test. Transactions in GIS, 22(3), 760-774.

Wheeler, A. P., Worden, R. E., \& McLean, S. J. (2016). Replicating group-based trajectory models of crime at micro-places in Albany NY. Journal of Quantitative Criminology, 32(4), 589-612.

Wheeler, A. P., Worden, R. E., \& Silver, J. R. (2019). The accuracy of the violent offender identification directive tool to predict future gun violence. Criminal Justice and Behavior, 46(5), 770-788.

Wyant, B. R., Taylor, R. B., Ratcliffe, J. H., \& Wood, J. (2012). Deterrence, firearm arrests, and subsequent shootings: A micro-level spatio-temporal analysis. Justice Quarterly, 29(4), 524-545.

Yang, M., Chen, Z., Zhou, M., Liang, X., \& Bai, Z. (2021). The special impact of COVID-19 on crime: A spatial temporal analysis in Chicago. ISPRS International Journal of Geo-Information, 10, 152-172.

Publisher's note Springer Nature remains neutral with regard to jurisdictional claims in published maps and institutional affiliations.

Gregory Drake is an assistant professor in the Criminology and Criminal Justice Department at Saint John Fisher College. He received his Ph.D. in Criminal Justice from Michigan State University. His research is focused on police and policing, in particular officer wellness, and criminal justice policy evaluation.

Andrew P. Wheeler is a Senior Data Scientist at HMS and an affiliated faculty member at Georgia State University in the Department of Criminal Justice and Criminology. He received his doctoral degree in criminal justice from the University at Albany SUNY. His research focuses on the applications of predictive policing and operations research within the criminal justice field.

Dae-Young Kim is an associate professor in the Criminal Justice Department at SUNY Buffalo State. His research interests include prisoner reentry, problem-based learning, criminal justice policy and program evaluation, and political economy of crime and punishment. His work has appeared in journals such as Criminal Justice and Behavior, Journal of Crime and Justice, Journal of Criminal Justice, Journal of Research in Crime and Delinquency, and The Prison Journal. 
Scott W. Phillips is a professor in the Criminal Justice Department at SUNY Buffalo State. He earned a $\mathrm{PhD}$ from SUNY Albany, and his research focuses on empirical examinations of police officer decision making and organizational influences on officer's behavior. His works have appeared in Journal of Criminal Justice, Police Research and Practice, Criminal Justice Policy Review, and Policing and Society. He has worked as the Futurist Scholar in Residence with the Behavioral Science Unit at the Federal Bureau of Investigation's National Academy in Quantico, Virginia.

Kathryn M. Mendolera is the lead crime analyst at the Erie Crime Analysis Center. She earned her Master of Science in Criminal Justice from the State University of New York at Albany. At the Erie Crime Analysis Center, she is assigned to shootings, and assists in investigations and analysis of all reported homicides and shooting incidents in Erie County. Through this work, she has twice received the Buffalo Mayor's Civilian Award of Merit. She has also taught courses in crime analysis and intelligence research methods at SUNY Buffalo State and Hilbert College. 